See Article page e143.

\section{Commentary: Measurement of the ascending aorta: $A$ picture is worth a thousand calipers}

\author{
Erin M. Iannacone, MD, and Leonard N. Girardi, MD
}

Aortic disease manifestations are varied, and may be identified or evaluated by a broad range of clinicians. Optimal timing of surgical intervention is imperative to avoid unnecessary life-threatening consequences, and is largely reliant on the measurement of the aortic diameter in the case of aneurysmal disease. Techniques for imaging aortic pathologies are numerous and evolving. ${ }^{1}$ Aortography, the former gold standard, has been largely replaced by lessinvasive techniques, including computed tomography (CT), magnetic resonance imaging, and transthoracic echocardiography (TTE) or transesophageal echocardiography (TEE). The recent Guidelines and Standards document from the American Society of Echocardiography and the European Association of Cardiovascular Imaging recommends only $\mathrm{CT}$ as a first-line imaging modality for thoracic aortic aneurysm. Magnetic resonance imaging and TTE are second-line recommendations, and TEE and aortography are third-line recommendations. ${ }^{2}$ It is rare that intraoperative findings will alter the surgical plan with regard to the ascending aorta, because the anatomy of the aorta is usually determined by preoperative imaging. Exceptions may include a novel finding of a dilated aorta when operating on valvular or coronary disease, in which case intraoperative measurement may assist in the decision of whether to replace the aorta.

The advent of computerized measurements is reported to have increased discrepancies in the measurement of the ascending aorta. ${ }^{1}$ Freeman and colleagues ${ }^{3}$ note that advancements such as echocardiography-gating, 3dimensional (3-D) datasets, and multiplanar reformatting and measurement offer an increased accuracy compared

\footnotetext{
From the Department of Cardiothoracic Surgery, Weill Cornell Medicine, New York, NY.

Disclosures: The authors reported no conflicts of interest.

The Journal policy requires editors and reviewers to disclose conflicts of interest and to decline handling or reviewing manuscripts for which they may have a conflict of interest. The editors and reviewers of this article have no conflicts of interest.

Received for publication Aug 19, 2020; revisions received Aug 19, 2020; accepted for publication Aug 20, 2020; available ahead of print Aug 28, 2020.

Address for reprints: Leonard N. Girardi, MD, Department of Cardiothoracic Surgery, Weill Cornell Medicine, 525 E 68th St, New York, NY 10065 (E-mail: lngirard@ med.cornell.edu)

J Thorac Cardiovasc Surg 2021;161:e147-8

$0022-5223 / \$ 36.00$

Copyright (C) 2020 by The American Association for Thoracic Surgery

https://doi.org/10.1016/j.jtcvs.2020.08.072
}

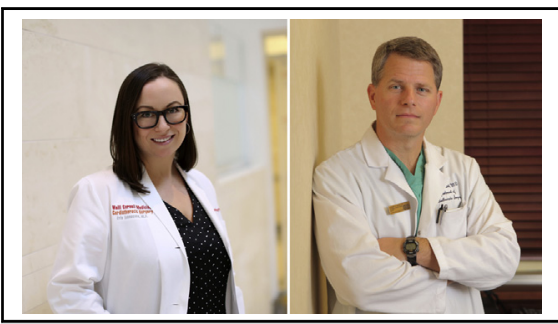

Erin M. lannacone, MD, and Leonard N. Girardi, MD

CENTRAL MESSAGE

The decision to recommend surgical management for aneurysmal aortic disease continues to require thoughtful evaluation of the patient and his or her imaging studies by the operating surgeon.

to imaging techniques in years past. The challenge lies in standardizing the techniques of measurement and reporting. Elefteriades and colleagues ${ }^{4}$ compare direct caliper measurement of the ascending aorta to findings on CT, TTE, and TEE in a cohort of 35 patients. ${ }^{4}$ From the CT images, they included in their analysis both orthonormal 3-D measurements, which ensure measurements taken perpendicularly to the long axis of the aorta, as well as the more traditional axial CT measurements. All the different measurements except those from TEE were comparable to the direct caliper measurements $(P>.05) .{ }^{4}$

The authors confirm accuracy and concurrence between CT, TTE, and intraoperative caliper measurements and question whether the interventional guidelines, based on axial measurements, may require adjusting. Statistical comparison of the axial and orthonormal measurements was not performed. However, the concordance of the measurements seen in this small series suggests against a relative underestimation of orthonormal measurements, cited elsewhere as a reason to support surgical intervention on smaller diameters. ${ }^{1,5}$ Perhaps the most clinically revealing question we should pursue is whether we can expect broader concordance between surgeon-generated measurements and radiologist-determined orthonormal 3-D measurements. The interpretation of imaging studies is a hallmark of surgical education, and aortic surgeons are unlikely to stop performing their own measurements of an imaged aorta. This is particularly true when the results determine whether or not to recommend surgical intervention, with all of the risks and benefits in balance. Rather than changing the guidelines to 
suit the new technology, we should examine if the thoughtful eye of an experienced aortic surgeon isn't already meeting the standard.

\section{References}

1. Elefteriades JA, Mukherjee SK, Mojibian H. Discrepancies in measurement of the thoracic aorta: JACC review topic of the week. J Am Coll Cardiol. 2020;76: 201-17.

2. Goldstein SA, Evangelista A, Abbara S, Arai A, Asch FM, Badano LP, et al. Multimodality imaging of diseases of the thoracic aorta in adults: from the American Society of Echocardiography and the European Association of Cardiovascular Im- aging: endorsed by the Society of Cardiovascular Computed Tomography and Society for Cardiovascular Magnetic Resonance. J Am Soc Echocardiogr. 2015;28: $119-82$.

3. Freeman LA, Young PM, Foley TA, Williamson EE, Bruce CJ, Greason KL. CT and MRI assessment of the aortic root and ascending aorta. AJR Am J Roentgenol. 2013;200:W581-92.

4. Vinholo TF, Zafar MA, Papanikolaou D, Chung J, Ellauzi H, Ziganshin BA, et al. Direct measurement of ascending aortic diameter by intraoperative caliper assessment. J Thorac Cardiovasc Surg. 2021;161:e143-6.

5. Ziganshin BA, Zafar MA, Elefteriades JA. Descending threshold for ascending aortic aneurysmectomy: is it time for a "left-shift" in guidelines? J Thorac Cardiovasc Surg. 2019;157:37-42.
See Article page e143.

\section{Commentary: Measure twice, cut once}

\author{
Jonathan C. Hong, MD, MHS, and \\ Joseph S. Coselli, MD
}

The risk of aortic rupture and dissection is directly related to the diameter of the aorta according to Laplace's law. For more than 2 decades, the natural history studies from the Aortic Institute at Yale-New Haven Hospital have emphasized the increased incidence of aortic complications at larger aortic diameters. ${ }^{1,2}$ Diameter-based aortic thresholds, based on radiographic findings, are a critical consideration for surgical decision-making and form the basis of the clinical practice guidelines for surgical repair. ${ }^{3}$ For asymptomatic patients, the timing of operative repair is largely determined by preoperative imaging studies;

From the Division of Cardiothoracic Surgery, Michael E. DeBakey Department of Surgery, Baylor College of Medicine; Department of Cardiovascular Surgery, Texas Heart Institute; and CHI St Luke's-Baylor St. Luke's Medical Center, Houston, Tex.

Disclosures: Dr Coselli's work is partly supported by the Cullen Foundation. Dr Coselli consults for, receives royalties and a departmental educational grant from, and participates in clinical trials for Terumo Aortic; consults and participates in clinical trials for Medtronic, Inc, and W.L. Gore \& Associates; and serves as a co-investigator for CytoSorbents. Dr Hong reported no conflicts of interest.

The Journal policy requires editors and reviewers to disclose conflicts of interest and to decline handling or reviewing manuscripts for which they may have a conflict of interest. The editors and reviewers of this article have no conflicts of interest.

Received for publication Aug 18, 2020; revisions received Aug 18, 2020; accepted for publication Aug 19, 2020; available ahead of print Aug 24, 2020.

Address for reprints: Joseph S. Coselli, MD, One Baylor Plaza, BCM 390, Houston, TX 77030 (E-mail: jcoselli@bcm.edu).

J Thorac Cardiovasc Surg 2021;161:e148-9

$0022-5223 / \$ 36.00$

Copyright (c) 2020 by The American Association for Thoracic Surgery

https://doi.org/10.1016/j.jtcvs.2020.08.059
Check for updates

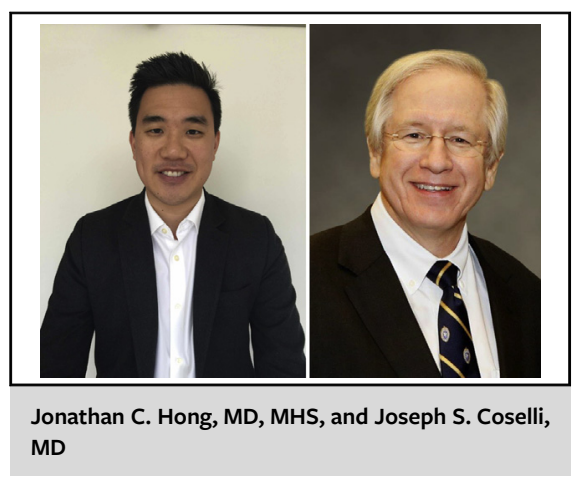

CENTRAL MESSAGE

Intraoperative direct caliper measurements of the ascending aorta correlate well with preoperative CT and TTE measurements at a high-volume aortic institution.

modalities include echocardiography (transthoracic [TTE] and transesophageal), computed tomography (CT), and magnetic resonance imaging. However, the ascending aorta can be challenging to image due to motion, oblique course, and variability of measurement techniques, as recently described by Elefteriades and coauthors. ${ }^{4}$

In this current issue of the Journal, Vinholo and coauthors ${ }^{5}$ from the Aortic Institute at Yale-New Haven Hospital compared intraoperative, direct caliper measurements to preoperative imaging studies, primarily CT and TTE measurements. In this study of 35 patients, preoperative measurements corresponded well with intraoperative measurements of the ascending aorta. Nuances of measurement included the exclusion of the aortic 